\title{
LAS MUJERES VENEZOLANAS Y LAS REVOLUCIONES: LA HISTORIA QUE SE ESCRIBE HOY
}

\author{
Elida Aponte Sánchez \\ Universidad de Zulia (Venezuela)
}

\section{RESUMEN}

La experiencia de las mujeres venezolanas, al igual que la del resto de mujeres del mundo, con respecto a las revoluciones políticas que han experimentado los países, no deja de ser paradójica. Formando parte del colectivo humano en más del cincuenta por ciento de la población, las mujeres hemos participado de tales situaciones de excepción. Sin embargo y a pesar del costo que ello ha significado para nosotras, llegamos al final con las manos vacías y con la ratificación de que la revolución feminista es la única que puede hacer realidad, los postulados de la democracia que reclamamos.

La revolución bolivariana que se vive en Venezuela no es la excepción, y escribir sobre ella es no sólo útil, sino necesario y oportuno, dada su emulación por otros países de América Latina, y el reclamo de adhesión de los hombres y de las mujeres.

Palabras clave: mujeres, hombres, revolución, Venezuela, democracia.

\section{ABSTRACT}

The experience of Venezuelan women, and of all of the women around the world, in relation to the political revolutions occurred in different countries is still paradoxical. Being more than fifty percent of the human collective population, women have participated in those situations without exception. However, and although it has had a very expensive price for us women, we have come to the end in the real history, empty handed and with the certainty that the feminist revolution is the only one that can make true the postulates of the democracy we claim for.

The Bolivarian revolution that has taken place in Venezuela is not exception, and writing about it is not only useful, but also necessary and pertinent, given its emulation for other Latin American countries, asking men and women to join.

Key Words: women, men, revolution, Venezuela, democracy. 


\section{Introducción.}

En el mundo se ensayan en la actualidad modelos nuevos de organización política. Así como Europa se ha empeñado en un modelo de integración económico y político, otros países como Venezuela, miran al pasado y retomando viejos materiales que parecían abandonados por el pensamiento y la filosofía jurídica-política, elaboran desde ellos nuevas propuestas de pensamiento político alternativo que, a un tiempo, justifiquen la revolución, no puedan ser asimiladas por los modelos neoliberales y sirvan de amalgama para proponer nuevas maneras de integración de países.

Lo interesante de la experiencia venezolana es que es un modelo que se está utilizando para la exportación, con posibilidades ciertas de establecer un consenso político en la zona latinoamericana que permita la superación de los límites de los Estados-Nación y la construcción de un marco de organización política regional.

Revisar cuanto ganamos o perdemos las mujeres en esa tentativa es el objeto de nuestras reflexiones, sobre todo de cara a una visión latinoamericana que bien pudiera hacernos perder mucho de lo logrado en temas como la igualdad, la ciudadanía y, en general, el ejercicio de derechos.

\section{Tratando de definir lo que es una revolución.}

El término revolución no es un término unívoco, aunque su uso es corriente y de una amplia aplicación. Es así como se habla de revolución científica, industrial, artística, jurídica, sexual o política. A la revolución se le han dedicado ríos de tinta no sólo desde la filosofía sino de otras ciencias. A nosotras(os) nos interesa para este artículo la revolución política. Esa que ya Aristóteles revisaba en el Libro Octavo de su obra La Política. En el texto, el filósofo estagirita, exponía que existían dos causas principales de las revoluciones en el mundo y dos direcciones revolucionarias opuestas: la demagogia y la oligarquía. La causa primera de las revoluciones la encontramos en todos los sistemas políticos, dada la diversidad de todas las constituciones. Todos los sistemas políticos, por diversos que sean, reconocen ciertos derechos y una igualdad proporcional entre los ciudadanos, pero todos en la práctica se separan de esta doctrina ${ }^{1}$. En otras palabras, Aristóteles anotaba la deficiencia de todos los sistemas políticos para hacer realidad los derechos y la igualdad proclamados por las Constituciones de los países. Ello lo llevó a concluir: "la desigualdad es siempre, lo repito, la causa de las revoluciones, cuando no tienen ninguna compensación los que son víctimas de ellas"2.

Lo interesante de la afirmación aristotélica es que aunque su autor estaba convencido de que la desigualdad es la causa de las revoluciones y que iguales para él sólo eran los varones libres, nunca pudo sospechar que la desigualdad en la que se encontraban las mujeres en Grecia con respecto a los hombres, pudiera, al paso de los siglos, dar lugar a la única revolución que afecta esencialmente a las relaciones de los hombres y las mujeres; aspecto asertivamente estudiado por la autora española María Ángeles Durán en su libro "Si Aristóteles levantara la cabeza" 3 .

Volviendo a la revolución y a su definición, desde el punto de vista político, con ella se da un desplazamiento del poder, por lo que presupone generalmente la violencia cruenta o incruenta, pero violencia al fin y al cabo. El desplazamiento del poder y la violencia, entonces, parecen ser ingredientes conexos del fenómeno revolucionario. Ello lo recoge el ius filósofo Nicolás López Calera cuando afirma que una revolución es:

Todo proceso de cambio social, fructífero o frustrado, que tiene por finalidad remover urgente, radical y totalizante los principios, estructuras e instancias de poder

\footnotetext{
${ }^{1}$ ARISTÓTELES. La Política. Colecc. Austral. Madrid, Espasa-Calpe, 1974, p. 208.

${ }^{2}$ Ibíd.

${ }^{3}$ DURÁN, María Angeles. Si Aristóteles levantara la cabeza. Madrid, Ediciones Cátedra, Universitat de Valencia, Instituto de la Mujer, 2000.
} 
de un sistema utilizando para ello, entre otros medios, la violencia o la amenaza de violencia ${ }^{4}$.

Sin embargo no se concibe una revolución política sin que ella apareje una revolución jurídica ya que toda revolución política es -principalmente- un acontecimiento jurídico que se propone de manera brusca y en breve tiempo, la conquista de nuevos derechos de carácter fundamental y la abolición de otros, considerados hasta ese momento como un privilegio de una determinada clase, hasta ese momento, dominante.

Con la revolución se da un cambio de paradigma a tenor del cual, un antiguo paradigma es reemplazado, completamente o en parte, por otro nuevo e incompatible. Ese proceso lo describe con maestría el autor Thomas S. Kuhn, cuando establece el paralelismo entre la revolución científica y la revolución política:

Las revoluciones políticas se inician por medio de un sentimiento, cada vez mayor, restringido frecuentemente a una fracción de la comunidad política, de que las instituciones existentes han cesado de satisfacer adecuadamente los problemas planteados por el medio ambiente que han contribuido en parte a crear (...) Tanto en el desarrollo político como en el científico, el sentimiento de mal funcionamiento que puede conducir a la crisis es un requisito previo para la revolución (...) Las revoluciones políticas tienden a cambiar las instituciones políticas en modos que esas mismas instituciones prohíben ${ }^{5}$.

No podemos hacer acopio en un artículo, limitado a unas cuantas cuartillas, de todas las expresiones autorizadas sobre la revolución, sin embargo, podemos resumir unas cuantas características, que la teoría política tradicional ha anotado en la definición de la revolución. A saber, A) Toda revolución está vinculada al problema del origen de la sociedad política organizada y ese origen está relacionado con la violencia. B) Una segunda característica de la revolución que se hizo presente a partir de la Revolución Norteamericana y de la Revolución Francesa, es la conciencia por parte de quienes participan en ella de hacer la historia, o sea, de que ante ellos se está realizando algo nuevo, desconocido y nunca antes narrado ${ }^{6}$. C) Toda revolución propugna la realización de ciertas ideas que tienen que ver con la felicidad, la libertad y la igualdad. D) Otra de las características de la revolución es que existiendo en toda sociedad políticamente organizada un grupo minoritario, los gobernantes, que dirigen al grupo mayoritario, los(as) gobernados(as) no hay revolución si no existe el objetivo político de cambiar la relación de subordinación. E) La quinta característica de la revolución está relacionada con el significado original del término "revolución". En sus inicios, la palabra "revolución" fue un término astronómico que logró relevancia en las ciencias naturales a partir de Copérnico, quien trató sobre la revolución en el espacio celestre o sideral. Pero será en el siglo XVIII cuando por primera vez hallamos la palabra "revolución" usada en sentido político, es decir, como una metáfora política para designar un movimiento de retroceso a un punto preestablecido y, por extensión, de reprogresión a un orden preordenado ${ }^{7}$. F) Para poder hablar de revolución es preciso que se den las condiciones objetivas que la hagan posible, la conciencia de la injusticia social. El proceso revolucionario demanda la conciencia de la injusticia social y la consiguiente quiebra de la relación del hombre con el orden social en vigor. Esta característica que comparten por igual la rebelión y la revolución, debe ser complementada en el proyecto revolucionario, con la instauración de un nuevo orden social. G) La finalidad del cambio que persigue la revolución

\footnotetext{
${ }^{4}$ LÓPEZ CALERA, Nicolás. Filosofía del Derecho. Granada, Editorial Comares, 1992, p. 41.

${ }^{5}$ KUHN, Thomas S. La estructura de las revoluciones científicas. Colecc. Breviarios. Agustín Contín (Trad.), México, Fondo de Cultura Económica, 1970, p. 149-151.

${ }^{6}$ ARENDT, Hanna. "Sobre la Revolución". En Revista Occidente. Pedro Bravo (Trad.), Madrid, 1967, p. 49.

${ }^{7}$ Ibíd.
} 
está centrado en que el mismo debe ser radical, de los principios, las estructuras y las instancias de poder de un determinado sistema social. H) Todo proyecto revolucionario aspira siempre a la igualdad real. Rememorando a Camus, "el ser humano revolucionario es consciente de que está vocado a ser libre e igual a sus semejantes, pero fácticamente no lo es" ${ }^{8}$. I) Toda revolución, desde el punto de vista jurídico-político, supone el derrocamiento de un gobierno y de una constitución legalmente establecida, por una clase social o un movimiento cuyo fin es cambiar la estructura social y la estructura política ${ }^{9}$. J) Toda revolución supone la quiebra de la continuidad con relación al ejercicio del poder constituyente y reclama una Constitución.

Las mujeres, por nuestra parte, hemos sido las protagonistas de una de las mayores revoluciones de los tiempos modernos. Una revolución que, en palabras de Almeida y Gallizo:

(...) una extraña revolución en la que no se ha derramado una gota de sangre (al menos de sangre ajena), de la que no ha perdurado el recuerdo de personajes singulares y heroicos cuya memoria honrar, que tampoco ha merecido grandes monumentos; una revolución que todavía no merece unas pocas líneas en los textos de la historia que se enseña en las escuela. Sin embargo, la revolución que han protagonizado las mujeres en este siglo ha sido la que más cosas ha hecho cambiar en la vida cotidiana de la gente y, sobre todo, la que ha producido cambios más irreversibles. Por tanto, es quizá la revolución que más en profundidad ha cambiado la sociedad ${ }^{10}$.

Nuestra revolución ha sido una respuesta propia al poder patriarcal, sin olvidar que con nuestro esfuerzo se han construido y logrado el éxito de otras revoluciones en el mundo, desde la era cristiana. La revolución feminista o la revolución de las mujeres, ha demandado siempre un igual reparto de papeles entre hombres y mujeres. El reclamo que durante siglos ha motivado la lucha de las mujeres y que caracteriza al feminismo en el mundo es la igualdad. La igualdad, que es también el derecho de derechos, ha nutrido la teoría, o mejor dicho, las teorías que han inspirado la revolución feminista y los movimientos de las mujeres en general. Por ello cuando en este artículo afirmamos que la revolución de las mujeres es la revolución feminista, es porque tomamos el feminismo en su significado habitual, ello es, como la doctrina de la igualdad de derechos para la mujer basada en la teoría de la igualdad de los sexos ${ }^{11}$.

La revolución feminista se ha enfrentado al patriarcado consciente de que es una cultura, un sistema, una civilización, un orden económico, un orden jurídico, etc. Pero además, y esto es muy importante, el patriarcado es un poder. Un poder que se expresa, como lo ha expuesto Kate Millet, microfísicamente, anidado en diferentes lugares, instituciones, personas, modelos políticos y económicos, hábitos, culturas, religiones e, incluso, al interior del alma de muchas mujeres. No es sólo un orden jurídico, político y económico, ni es sólo una cultura aunque también lo sea. ${ }^{12}$

La revolución feminista está alimentada por un conjunto de teorías que se oponen al patriarcado a partir de las reflexiones que realiza el movimiento feminista desde todas las áreas del conocimiento y por una práctica política. De tal manera que si dicha revolución, la más profunda de la historia de la humanidad, se impone alguna vez, afectará a los órdenes económicos, políticos y jurídicos y a la estructura sociocultural de los hombres y de las mujeres.

\footnotetext{
${ }^{8}$ CAMUS, Albert. L’Homme Révolté. S/L. Gallimard, 1951, p. 13.

${ }^{9}$ MARCUSE, Hebert. Ética de la Revolución. Madrid, Taurus Ediciones S.A., 1969, p. 142-143.

${ }^{10}$ ALMEIDA, Cristina y GALLIZO, Mercedes. "Para las mujeres, un paso a la derecha significa dos pasos atrás". En http//www.mujeresenred.nodo50.es. Consulta el 26 de julio de 2006.

11 EVANS, Richard J. Las feministas. Los movimientos de emancipación de la mujer en Europa, América y Australia. Madrid, Editorial Siglo XXI de España, 1980, p. 8.

${ }^{12}$ MILLET, Kate. Sexual Polítics. New Cork, Avon Brooks, 1971, p. 10.
} 
He sostenido, como características puntuales de la revolución feminista, que a) es una revolución necesaria, atípica, total y permanente, b) es una revolución progresiva y c) es una revolución autónoma.

La revolución feminista es necesaria, atípica, total y permanente, progresiva y autónoma, cuyo triunfo dará como resultado un nuevo modelo social, político y jurídico. Es una revolución que permite recobrar un extraordinario potencial humano, al tiempo que desarrolla la igualdad, la libertad, la ciudadanía, la justicia y la democracia.

Cuando afirmo que la revolución feminista es una revolución necesaria, quiero significar que la misma responde a un mandamiento ético, a un imperativo moral; de ahí que sea necesaria. Desde el punto de vista jurídico tiene justificación en lo que Simone Weil denomina los deberes que constituyen la base del derecho ${ }^{13}$. Para Weil, las obligaciones universales del hombre hacia sus semejantes nacen de las necesidades universales y estas pueden ser, necesidades físicas y necesidades del alma. Las necesidades de alimentarnos, de dormir, de tener un espacio propio, de cuidados médicos, son necesidades físicas; en tanto existen otras necesidades que no atienden a la vida física sino a la vida moral. Entre esas necesidades espirituales se encuentra la igualdad.

La igualdad es para Weil una necesidad moral que toda sociedad está obligada a cumplir para ser considerada o definida como tal ${ }^{14}$. Si la igualdad es una necesidad, entonces, la lucha revolucionaria que la reivindica, la revolución feminista, es también necesaria desde el punto de vista moral. La doctrina revolucionaria feminista tiene su asidero en el reclamo de que no se concibe una sociedad como justa cuando discrimina por el sexo a la mitad de los miembros que integran la comunidad, integrada por las mujeres.

La revolución feminista es una revolución atípica porque supera los pedimentos de todas las otras revoluciones conocidas y es total porque construye un verdadero universalismo. No por casualidad, John Stuart Mill sostuvo que el sometimiento de las mujeres no es un anacronismo inofensivo. El sometimiento de las mujeres impide positivamente el progreso de la raza humana por negar la sociedad el uso de sus talentos a la mitad de sus miembros, y por el efecto moralmente corruptor del poder inmerecido que da a los hombres. La única escuela del sentimiento moral auténtico es una sociedad de iguales, dirá Mill ${ }^{15}$.

La revolución feminista no se limita, como otras revoluciones, a la rotura de un cerco constitucional, ni a la quiebra de la continuidad con relación al ejercicio del poder constituyente, lo que pondría en duda, desde el punto de vista de la filosofía política tradicional y constitucional de si dicha revolución es auténtica. Nuestra revolución propone la reelaboración de toda la teoría sobre el poder constituyente y los conceptos de los cuales se nutre: pueblo, soberanía, voluntad general, por nombrar algunos.

Desde otro punto de vista, aunque el proyecto revolucionario feminista ha tenido como eje la igualdad de las mujeres y los hombres, no se limita a ello, por lo que propone un nuevo contrato social, distinto al contrato social originario y por ello mira a la Constitución como metáfora. No siempre las feministas miraron al contrato social originario para ponerlo en cuestión, contribución que le debemos a Carole Pateman ${ }^{16}$.

Hasta la década de los noventa del siglo veinte, las mujeres feministas en los distintos países habíamos dado la pelea en materia legislativa, apuntando nuestro arsenal de razones contra los códigos civiles, los códigos penales, las leyes especiales, etc., pero es recientemente cuando hemos tomado conciencia que es necesario revisar las constituciones y hacer del sexo una categoría sospechosa, siempre y en todos los casos.

La revolución feminista ha ido poniendo en cuestión y rompiendo de manera progresiva con las estructuras fundamentales de la sociedad, de tal manera que puedan satisfacer las

\footnotetext{
${ }^{13}$ WEIL, Simone. Descifrar el silencio. Colecc. Estructuras y Procesos. Madrid, Editorial Trotta, 1995, p. 74.

${ }^{14}$ Ibíd.

${ }^{15}$ MILL, John S. De la libertad. Madrid, Tecnos, 1995, p. 22.

${ }^{16}$ PATEMAN, Carole. El contrato sexual. María Luisa Femeninas (Trad.), Colecc. Filosofía Política, Pensamiento CríticoPensamiento Utópico. México, Editorial Anthropos, 1995.
} 
necesidades sentidas por el conglomerado humano femenino, sin que tal tarea pueda considerarse acabada, ni siquiera satisfactoria. Aún perviven instituciones como el matrimonio, la prostitución y la heterosexualidad obligatoria que son muestra indiscutible de la buena salud que goza el patriarcado; por lo que la revolución feminista es, en ese sentido, una revolución en proceso, inacabada.

De lo dicho, es fácil inferir que la revolución feminista no plantea un nuevo comienzo, ni un retorno hacia atrás, hacia tiempos vividos o experimentados por la especie humana como sí hacen las otras revoluciones. Ello es así porque la historia que narra no ha sido narrada antes, de ahí que nuestra revolución esté haciendo siempre su propia historia.

La revolución feminista es una revolución progresiva porque los reclamos de las mujeres han adaptado su vindicación a la resistencia del patriarcado y a las situaciones políticas existentes en los distintos países. Las acciones y las creencias de las revolucionarias feministas no han sido el resultado de una simple pasión por la igualdad femenina, han sido -también- el resultado de un complejo entramado de elementos políticos e ideológicos, entre los cuales el deseo de liberación de la mujer, ha sido uno de tantos. La historia de la revolución feminista es, en cierta manera, la historia de una demanda progresivamente ampliada. Así como Karl Marx proclama en su Mensaje a la Liga Comunista en 1850 que la revolución debía proseguir de un modo permanente hasta la realización del socialismo, las feministas proclamamos que la revolución debe continuar hasta el logro del último objetivo propuesto. En ese sentido, la tarea que compromete al feminismo es teórica-crítica y, además, la práctica contemporánea más importante para las mujeres y, en consecuencia, para la humanidad.

La revolución feminista es una revolución autónoma porque aunque las mujeres hemos contribuido a la consolidación de las otras revoluciones y éstas, tanto las de derecha como las de izquierda, han querido interdictar la revolución feminista y ponerla al servicio de sus propios libretos, ninguna revolución ha concretado una agenda satisfactoria con respecto a las mujeres. Y ello es así porque el único punto en el cual han coincidido los revolucionarios de derecha y de izquierda, de oriente y occidente, los teóricos liberales y antiliberales, es que han aceptado que el confinamiento de las mujeres en la esfera doméstica se justifica por la naturaleza particularista, emocional e introspectiva de ellas.

La experiencia ha demostrado que cuando las feministas unimos nuestros esfuerzos o lucha revolucionaria a corrientes políticas de mayor envergadura, especialmente en tiempos de excepción como las revoluciones, pensando que de esa manera logramos también nuestros objetivos, hemos salido debilitadas y con las manos vacías. Por ello, para las feministas, la autonomía revolucionaria es una garantía de nuestra revolución.

Era a menudo difícil que las feministas salieran ganando en el pacto con sus aliados, quienes las obligaban con frecuencia a adoptar sus propias creencias políticas sin ofrecer a cambio demasiado apoyo a los objetivos feministas ${ }^{17}$.

La anterior afirmación no ha perdido su vigencia hasta el día de hoy.

\section{La Revolución Bolivariana de Hugo Chávez Frías.}

Si existe un país en el mundo, cuya historiografía recoge revoluciones, ese es Venezuela. A la Revolución de la Independencia que nuestro país librara en contra de la Monarquía española, desde finales del siglo XVIII y parte del siglo XIX, han seguido un sin fin de situaciones que sus protagónicas autodenominaron: revoluciones. Así la historiografía nacional recoge la Revolución Azul, la Revolución Federal, la Revolución Restauradora, la Revolución Libertadora y otras, acaecidas en distintas épocas y bajo distintos caudillismos. Sin embargo, es durante el lapso comprendido entre el año 1999 y el 2006 cuando se ha hablado con insistencia

${ }^{17}$ EVANS, Richard J. Ob. Cit., p. 43. 
de la revolución bolivariana, liderada por el Presidente Hugo Chávez Frías, cuya vocación no se limita al espacio geográfico de Venezuela sino que se ofrece como alternativa continental, imitable y defendible. Ello explica que países como Bolivia, pretendan cumplir la misma bitácora revolucionaria que se cumplió en Venezuela, iniciando su andar bajo el gobierno de Evo Morales, con la convocatoria a una asamblea constituyente.

Es importante aclarar que desde el punto de vista ideológico la revolución bolivariana ha ensayado varios modelos políticos, siendo en la actualidad el modelo castro-fidelista, también denominado socialismo del siglo XXI, el que está presente en los discursos y algunas ejecutorias del gobierno nacional. Si Cuba miró a Rusia como su modelo revolucionario, Hugo Chávez Frías mira a Cuba como su modelo, lo reinterpreta, lo enaltece y lo promueve como un mar de felicidad para el pueblo venezolano. Es oportuno decir aquí que el término revolución no fue utilizado por Hugo Chávez Frías durante la campaña electoral que lo llevó a la Presidencia en 1998, en ejercicio el pueblo venezolano del voto directo, universal y secreto.

Desde el punto de vista histórico, la revolución bolivariana remite a cuatro momentos cumbres, hasta hoy: 1) su introducción o anuncio en la asamblea nacional constituyente (julio de 1999). 2) su inicio con la Constitución aprobada por referéndum el 15 de diciembre de 1999, 3) la primera etapa de su desarrollo, en la cual el Presidente de la República y el Presidente de la Sala Constitucional del Tribunal Supremo de Justicia, acudieron a darle contenido y sostenimiento en el tiempo, y 4) la segunda etapa, esta que vivimos hoy, en el preludio de unas elecciones para elegir Presidente de la República, en la cual el candidato presidente ha adelantado que de resultar victorioso se reformará la constitución y se implementarán medidas que hagan realidad ese socialismo del siglo XXI que, dicho sea de paso, nadie ha definido ni sistematizado con claridad, desde el gobierno.

Durante todo el tiempo pero sobre todo durante el último año, la Asamblea Nacional (unicameral) y el mismo Presidente, han ido aprobando leyes y decretos-leyes que sirven de canales de ejecución y normalización a las decisiones que se han ido tomando progresivamente y que afectan, entre otros derechos, la propiedad privada.

Hemos sostenido que el ciclo revolucionario del presidente Hugo Chávez Frías, y que algunas(os) se oponen a llamarlo bolivariano, en contraposición a otras revoluciones socorridas, no cierra con la Constitución sino que se inicia con la Constitución. Con el referente de la revolución bolivariana y por la vía constitucional-electoral, Hugo Chávez Frías desplazó del poder a una oligarquía nacida de la connivencia de los partidos políticos y produjo una nueva Constitución. Según Marcuse, ambos elementos definen la revolución desde el punto de vista constitucional ${ }^{18}$.

Una Constitución, la venezolana de 1999, que si bien está cargada de un hondo contenido social y de respeto a los derechos humanos -incluyendo los reclamos feministas y de los pueblos indígenas- como corresponde al Estado Constitucional que promueve, no es una Constitución socialista, ni contiene ningún proyecto económico acorde con la herencia marxista leninista. Sin embargo, revolución es la palabra repetida que invocan los(as) revolucionarios(as) venezolanos(as) sin conocer su contenido preciso. En ese variopinto universo, los marxistascomunistas, los socialistas, el partido Patria Para Todos, el partido V República y así el resto de los grupos políticos afectos al gobierno tienen sus propias percepciones, ajustadas en última instancia a lo que diga, decida, interprete y ordene, desde la presidencia de la República, el comandante. Es importante acotar que el Presidente Hugo Chávez Frías ha llamado a todos los partidos que lo apoyan a unirse en un partido único, de contenido socialista, punto que aún no ha sido debatido ni acordado.

La revolución bolivariana, como otras revoluciones, dice que aspira la realización de ciertas ideas, tales como: la felicidad del pueblo, la igualdad, la justicia social, el disfrute de las riquezas bajo el eslogan: "ahora Venezuela es de todos", o la afirmación "todo el poder para el

\footnotetext{
${ }^{18}$ MARCUSE, Hebert. Ob. Cit., p. 18.
} 
pueblo, todo el poder para los pobres". La revolución bolivariana, a diferencia de otras revoluciones, es adelantada por un acuerdo cívico-militar que dice estar legitimado por la voluntad del pueblo. Y, en este punto, no deja de ser paradójico los diversos contenidos que ese término pueblo, de suyo difícil de definir, tiene en la revolución chavista, según lo defina el Presidente de la República, la Sala Constitucional del Tribunal Supremo de Justicia o un Canciller en funciones. De cualquier manera, en la interpretación que hacen el líder y sus seguidores, el pueblo pareciera estar compuesto, en época no electoral, por quienes comparten la revolución, no la cuestionan ni la critican, ni se oponen a sus deseos. Y, en la época electoral, el pueblo es el universo electoral.

\section{Lo que las mujeres venezolanas consagramos en la Constitución de 1999.}

El Movimiento de Mujeres de Venezuela, representado por distintos grupos y organizaciones de mujeres, en el cual confluyeron tanto tendencias liberales como socialdemócratas, entendió la importancia del momento constituyente de 1999 para consagrar los reclamos que venían siendo reconocidos en sendos instrumentos nacionales e internacionales, sobre los derechos humanos de las mujeres. Era una oportunidad inédita, sobre todo tomando en consideración que la revolución bolivariana reclamaba una nueva Constitución.

Las mujeres venezolanas organizadas y concienciadas miramos a la Constitución como instrumento que permite lograr la organización política y jurídica de la sociedad, indispensable para la existencia del Estado de Derecho. En ello, teníamos presente la afirmación de Olympe De Gouges, citada por Alicia Puleo, cuando afirmó:

“(...) En toda sociedad en la que la garantía de los derechos no está asegurada, ni la separación de los poderes determinada, no tiene constitución; la constitución es nula si la mayoría de los individuos que componen la Nación no ha cooperado en su redacción (...)”19.

Sin embargo, según lo explano en algunos de mis artículos (2005), aunque el momento constituyente era la oportunidad ideal para consagrar en la máxima ley nuestros reclamos, teníamos el temor -y la experiencia nos lo ha ratificado- de que las mujeres no éramos percibidas ni tenidas como un factor de poder, no obstante integrar más del cincuenta por ciento de la población venezolana. En otras palabras, el momento constituyente no nos permitió dejar de ser las constituidas. Y sería la práctica constitucional posterior, la que daría contenido al tema de los derechos de las mujeres consagrado en la Constitución de 1999, práctica que siempre ha mirado a las necesidades e intereses de los varones y que, forzoso es decirlo, nos ha decepcionado.

Este punto, que sólo pincelamos en el artículo, puede ser un material útil para referirnos a la Constitución como un instrumento de gobierno, lo que sugiere la idea de una clase sexual gobernante (los varones) que utiliza la Constitución como instrumento del poder que ejerce sobre otra clase sexual gobernada (las mujeres).

En otras palabras, aunque el momento constituyente fue una excelente oportunidad de confluencia de pedimentos entre la revolución feminista y la revolución bolivariana, en lo referente a los derechos de las mujeres, no es menos cierto que pasado ese momento de consagración textual de derechos, el divorcio entre ambas revoluciones es cada vez más claro e indiscutible.

Este aspecto es de suma importancia. La Constitución de un país es el pacto social por excelencia y para las mujeres, los derechos consagrados en el texto constitucional, nos corresponden a causa de ser mujeres, de ser ciudadanas y no a pesar de nuestro sexo, como

\footnotetext{
${ }^{19}$ PULEO, Alicia. La ilustración olvidada. La polémica de los sexos en el siglo XVIII. Colecc. Cultura y Diferencia, No. 81. Barcelona, Anthropos, 1993, p. 159.
} 
recitan los textos constitucionales y todas las leyes de paridad; punto que ha estudiado con maestría Lía Cigarini ${ }^{20}$.

El Estado se organiza a través de la Constitución y las feministas estamos convencidas que no es posible la igualdad entre los sexos si el Estado sigue siendo masculino, si la sexualidad sigue siendo un asunto regulado por el derecho penal, sin trascendencia para el derecho constitucional. Y esto lo afirmamos porque si los sexos fueran iguales, las mujeres no estaríamos sometidas sexualmente y no sería necesaria una revolución, teniendo presente que la fuerza en el sexo no es excepcional ${ }^{21}$.

Ahora bien, la asamblea nacional constituyente de 1999 fue la oportunidad para visibilizar a las mujeres como sujetas políticas, como ciudadanas, sin que dicha visibilización las hiciera constituyentes. Fue así como, aprovechada la coyuntura, se logró consagrar en el texto constitucional todos los pedimentos que constituían la agenda feminista venezolana, adelantada, en algunos aspectos, en leyes especiales que habían mostrado poca efectividad, aprobadas entre 1980 y el año 1998.

Por otra parte, el proceso revolucionario liderado por Hugo Chávez Frías -como todo proceso revolucionario- debía dar la idea de modernización y qué mejor manera de hacerlo que visibilizando a los grupos que por tradición estaban excluidos de los textos constitucionales: los pueblos indígenas, las familias, las mujeres, los(as) ancianos(as), los(as) discapacitados(as), entre otros.

La visibilización de los(as) nuevos(as) sujetos(as) en la Constitución venezolana de 1999 se hace desde una postura garantista de los derechos humanos y con el fin de consolidar una sociedad democrática, participativa, protagónica, multiétnica y pluricultural, como reza el preámbulo de la Constitución. Sin embargo, si hacemos la revisión histórica de tales nociones y el contenido político que se le ha dado a las mismas, en una sociedad que ha construido sus valores sobre el patriarcado, tomamos conciencia de que tal sociedad no está mirando precisamente hacia las mujeres, pese a afirmar que se tiende al aseguramiento de la igualdad, sin discriminación ni subordinación alguna.

Dejando a salvo lo dicho, las mujeres venezolanas logramos, entre otros, consagrar los siguientes derechos en la Constitución, producto de la asamblea constituyente de 1999. Haremos sólo una enunciación no limitativa de tales derechos y logros. En primer término, la Constitución de 1999 se encuentra transversalizada por el lenguaje de género, es decir, el texto constitucional -con excepción del preámbulo- está redactado en un lenguaje no sexista e inclusivo de las mujeres, lo que hace de la igualdad de los hombres y las mujeres su pivote ideológico. Partiendo de esa igualdad en el lenguaje, se afirma además que: 1) La República Bolivariana de Venezuela es irrevocablemente libre e independiente y fundamenta su patrimonio moral y sus valores de libertad, igualdad, justicia y paz internacional, en la doctrina de Simón Bolívar, el Libertador (Art. 1). Dejando dicho que el Libertador Simón Bolívar no aceptó nunca la igualdad de los hombres y de las mujeres. Pero, de cualquier manera, el valor igualdad es recogido en el texto constitucional como un valor fundamental.

De igual manera, el artículo 2, propugna que Venezuela se constituye en un Estado democrático y social de Derecho y de Justicia. Este aspecto es de suma importancia porque la justicia no es más que la realización de la igualdad material. En otras palabras, además de la igualdad formal, la Constitución aspira a realizar la igualdad material o justicia. En con ese compromiso que avanzamos en el artículo 21 en la separación entre la igualdad formal y la discriminación. Es decir, además de asumir que todas las personas son iguales ante la ley, se establece que: a) no se permitirán discriminaciones fundadas en la raza, el sexo, el credo, etc., o aquellas que, en general, tengan por objeto o por resultado anular o menoscabar el reconocimiento, goce o ejercicio en condiciones de igualdad, de los derechos y libertades de toda

\footnotetext{
${ }^{20}$ CIGARINI, Lía. La política del deseo. Barcelona, Icaria, 1996, p. 16.

${ }^{21}$ MACKINNON, Catherine. Hacia una teoría feminista del Estado. Colecc. Feminismos. Eugenia Martín (Trad.). Madrid, Ediciones Cátedra, 1995, p. 391.
} 
persona y b) se establece que la ley garantizará las condiciones jurídicas y administrativas para que la igualdad ante la ley sea real y efectiva; adoptará medidas positivas a favor de personas o grupos que puedan ser discriminados, marginados o vulnerables, protegerá especialmente a aquellas personas que por alguna de las condiciones antes especificadas, se encuentren en circunstancia de debilidad manifiesta. Con este artículo, la asamblea constituyente venezolana de 1999, por pedimento del Movimiento de Mujeres positivizó en el texto constitucional las obligaciones que ya había asumido el Estado venezolano en relación a la Convención Internacional para la Eliminación de todas las formas de Discriminación contra la Mujer (CEDAW).

Otro logro en la Constitución de 1999 fue que por primera vez se reconoce en el texto constitucional que las relaciones familiares se basan en la igualdad de derechos y deberes, la solidaridad, el esfuerzo común, la comprensión mutua y el respeto recíproco a sus integrantes (Art. 75) y que existen varios modelos de familias, distintos a la familia monogámica tradicional. Ello ha permitido visibilizar la enorme cantidad de familias monoparentales en las cuales la mujer es, a un tiempo, madre y padre; lo que es una constante en la sociedad venezolana. Por otra parte, se constitucionaliza en el texto de 1999 la igualdad absoluta de derechos y deberes de los cónyuges en el matrimonio y se reconoce que las uniones estables de hecho entre un hombre y una mujer que cumplan los requisitos establecidos en la ley, producirán los mismos efectos que el matrimonio (Art. 77).

Un avance muy importante y que no existe en ninguna Constitución de América Latina es que por primera vez se reconoce que el trabajo del hogar es una actividad económica que crea valor agregado y produce riqueza y bienestar social (Art. 88). Este sólo artículo marca un enorme salto adelante en la concepción del aporte del trabajo de las mujeres en el hogar a la riqueza del país y a las cifras del producto territorial bruto. Otra historia del derecho laboral habrá que escribir a partir de la consagración del artículo 88, aunque hasta el presente no ha sido implementado. Además, fue posible consagrar en la Constitución que toda persona tiene derecho a una educación integral, de calidad, permanente, en igualdad de condiciones y oportunidades, sin más limitaciones que las derivadas de sus aptitudes, vocación y aspiraciones (Art. 103).

\section{Lo logrado hasta hoy.}

Ahora bien, al texto constitucional no ha seguido la igualdad material o justicia, existiendo en la actualidad una grave contradicción entre la constitución formal, el texto constitucional y la constitución real. Se repite la constante histórica de que a la legislación no ha seguido la jurisdicción. Todos los poderes públicos: ejecutivo, legislativo, judicial, electoral y ciudadano siguen anclados en una interpretación sexista de la Constitución y del ordenamiento jurídico; conducta que no sólo está vaciando de contenido al texto fundamental sino que sigue promoviendo una situación de indefensión de las mujeres y la impunidad en materias de tanta importancia como, por ejemplo, la violencia de género. Esa situación demuestra que hay un problema de fondo con la revolución bolivariana y que tiene que ver directamente con la democracia y la construcción de la ciudadanía de las mujeres. Mientras las mujeres no logremos el ejercicio pleno de la ciudadanía, aunque nominalmente aparezcamos como integrantes del pacto constituyente y por ende, suscritoras de la Constitución, seguiremos siendo lo que he denominado pueblo excluido, tratadas como idénticas mas no iguales, en palabras de Celia Amorós $^{22}$.

El tema tiene importancia en los nuevos Estados democráticos porque hace apenas algunos años que las mujeres miramos a la Constitución, al pacto constituyente como puerta de entrada a la ciudadanía. Sin embargo si esa ciudadanía no es construida sobre la igualdadparidad, es imposible la consolidación de la democracia.

\footnotetext{
${ }^{22}$ AMORÓS, Celia. Mujer: participación, cultura política y Estado. Buenos Aires, Ediciones de La Flor, 1990.
} 
La experiencia venezolana a partir de 1999 ha puesto de manifiesto para las mujeres que los problemas constitucionales no son, primariamente, problemas de derecho sino problemas de poder.

El proyecto de organización económica, jurídica y política que reclaman los nuevos Estados revolucionarios necesita la elaboración de un nosotros(as) a partir de un modelo democrático y ciudadano. Esa elaboración de un nosotros(as) no puede darse para el feminismo sino sobre la base de la paridad. La paridad es una propuesta política que, en palabras de Rosa Cobo, ataca el núcleo básico de la democracia patriarcal al proponer una nueva distribución del poder entre varones y mujeres ${ }^{23}$.

La Constitución venezolana de 1999 habla de democracia y de igualdad de géneros pero es necesario acompañar su articulado de la estrategia de la paridad, a tenor de la cual, los operadores y las operadoras de la justicia y toda autoridad pública deben entender que el interés por lo público y lo político, y la tarea que se deriva de ese interés, debe recaer igualmente en varones y mujeres.

Es necesario, para que las normas de la Constitución no devengan en normas-fachada, que quienes detentan el poder público en la revolución bolivariana entiendan que la democracia participativa y protagónica y el estado social y democrático, de Derecho y de Justicia, a los que alude el Preámbulo de la Constitución no se pueden construir de espaldas a las mujeres y mucho menos en contra de ellas.

Hablar de democracia participativa y protagónica supone una ciudadanía activa ocupada en asambleas, discusiones, debates, como bien lo ha expresado Alicia Miyares. Es decir, una ciudadanía reflexiva que pueda manifestar por todos los medios cívicos la conformidad o inconformidad con las decisiones gubernamentales y la garantía que participarán en ellas tanto los hombres como las mujeres, de manera paritaria ${ }^{24}$.

Si la promesa de la revolución bolivariana de construir una sociedad democrática, igualitaria, participativa, protagónica, pluricultural y multiétnica no da paso a las mujeres, será, como tantas otras, una revolución fallida.

${ }^{23}$ COBO, Rosa. Feminismo y Democracia Paritaria. En El Viejo Topo. No. 158. Noviembre de 2001. Madrid, p. 63.

${ }^{24}$ MIYARES, Alicia. Democracia feminista. Madrid, Ediciones Cátedra, 2003, p. 16. 